\title{
CIRCULACIÓN DE OBJETOS PERFORADOS DE CONCHA: APORTES PARA LA INTERPRETACIÓN DE SU ROL EN LAS RELACIONES SOCIALES DEL DESIERTO DE ATACAMA ENTRE LOS 6000-3500 AP
}

\author{
CIRCULATION OF PERFORATED SHELL OBJECTS: FURTHER \\ CONSIDERATIONS FOR INTERPRETING THEIR ROLE IN SOCIAL RELATIONS \\ IN THE ATACAMA DESERT FROM 6000-3500 вP
}

Catalina Soto ${ }^{a}$, Ximena Power $\&$ Benjamín Ballester ${ }^{c}$

El estudio de objetos perforados de cuatro sitios arqueológicos datados entre el 6000 y $3500 \mathrm{AP}$, ubicados en la costa y tierras altas del desierto de Atacama, Región de Antofagasta, Norte de Chile, evidenció el uso predominante de valvas de moluscos del océano Pacífico para su fabricación. Estos datos, en conjunto con la información arqueológica disponible para la zona, permiten discutir sobre la circulación de estos objetos entre costa y puna, y sobre la sistematización del intercambio entre comunidades durante el Período Arcaico Tardío en la macrozona.

Palabras clave: objetos perforados de concha, circulación, Arcaico Tardío, desierto de Atacama.

The study of perforated objects from four archaeological sites on the Atacama Desert coast and highlands (Antofagasta Region, Northern Chile), dated between 6000 and 3500 BP, showed a predominant use of Pacific Ocean mollusks. These data, combined with available archaeological information about the area, provide inputs for a discussion of the circulation of such objects between the Pacific coast and the Puna, as well of the systematization of inter-community exchanges in the macro zone during the Late Archaic Period.

Keywords: perforated shell objects, circulation, Late Archaic, Atacama desert.

\section{INTRODUCCIÓN}

Diversos estudios antropológicos y arqueológicos han demostrado la importancia de cierta categoría de objetos en la mantención y reproducción de las relaciones sociales de grupos humanos con diferentes niveles de complejidad social (Webb 1974, Kohl 1975, Godelier 1976, Dupré \& Rey 1978, Mauss 1979, Sahlins 1983, Malinowski 1986, Hirth 1996, Lazzari 1999, Earle 2002, Trubitt 2003, Patterson 2005). Dichos bienes no relacionados directamente con el ámbito de la subsistencia han sido denominados en arquelogía como suntuarios, de prestigio y/o exóticos (Peregrine 1991, Hayden 1998), y regularmente aparecen vinculados a contextos de tipo religioso, simbólico, político y/o identitario. Así, se integran de manera activa en redes de circulación a escalas espaciales amplias (Lazzari 2005, Nielsen 2007, Smith 2013).

La aparición de objetos exóticos circulantes en el desierto de Atacama se ha observado en yacimientos característicos de los períodos prehispánicos más tempranos. Algunos de estos elementos son las valvas de

\footnotetext{
A Catalina Soto, Centro de Estudios Culturales Latinoamericanos CeCLA, Universidad de Chile, email: cata.sotorodriguez@gmail.com

B Ximena Power, Instituto de Investigaciones Arqueológicas y Museo IIAM, Universidad Católica del Norte, email: anneke.xp@gmail.com

c Benjamín Ballester, umR 7041 ArScAN, Équipe Ethnologie Préhistorique, Université Paris 1 Pantheón Sorbonne, París, Francia, email: benjaminballesterr@gmail.com
} 
moluscos y otros artefactos fabricados con esta materia prima, detectados en lugares alejados de su origen, como en el sitio de Tambillo en las tierras altas de la Región de Antofagasta (Núñez \& Santoro 1988, Núñez et al. 2006). Sin embargo, no es sino hasta el Período Arcaico Tardío (circa 6000-3500 AP) que los objetos perforados de concha circularon de manera masiva desde la costa del Pacífico hacia la puna de Atacama (Núñez 1982; Soto 2006, 2010; de Souza et al. 2010; Ballester \& Gallardo 2011). Esta tecnología enunciará la posterior producción sistemática de objetos perforados con diversas materias primas en la subárea circumpuneña (Rees 1999; Rees \& de Souza 2004; López \& Escola 2007; Carrión 2010, 2015; Soto 2010, 2015b; Westfall et al. 2010; Ballester \& Clarot 2014; Gallardo et al. 2016).

En este trabajo se denomina "objetos perforados" a todos aquellos artefactos pulidos que presentan una horadación y que suelen ser parte de collares, colgantes $y$ aplicaciones en otras superficies, tales como vestidos, diademas y turbantes, en su mayor parte con una función primaria de carácter ornamental (Soto 2015a). Dichas piezas han sido tradicionalmente clasificadas como "misceláneas" y denominadas como cuentas o adornos, los que según los contextos de su hallazgo parecen ser parte de los códigos visuales relacionados con lo ritual y con la ornamentación y puesta en escena de la corporalidad (embodiment) de individuos y/o grupos (Joyce 2005, Price 2008, Domingo et al. 2009). En el desierto de Atacama estos objetos son registrados prácticamente en toda la secuencia cronológica formando parte de collares, brazaletes, aplicaciones en telas e incrustaciones en objetos de madera. Asimismo, es notable su rol como bienes de intercambio o en ajuares y ofrendas de contextos fúnebres (Latcham 1938; Mostny 1964; Spahni 1967; Núñez 1971; Rees 1999; Rees \& de Souza 2004; Yacobaccio 2006; García-Alvarido 2007; Carrión 2010, 2015; Ballester \& Clarot 2014; Carrasco et al. 2015; Soto 2015a). En nuestro caso, hemos decidido utilizar el término objeto perforado porque, si bien en la costa se identifica su utilización como cuenta o parte de los conjuntos que componen collares, en el interior esta función no está clarificada del todo.

El presente artículo aborda la proliferación y circulación de estos objetos en el desierto de Atacama durante el marco temporal de los 6000-3500 AP, mediante el estudio de diferentes contextos asignables a dicha cronología. Específicamente, se plantea evaluar las similitudes y diferencias entre los conjuntos de objetos perforados, completos y terminados, de dos sitios de la costa desértica: Caleta Bandurrias y Punta Negra 1a; y dos de la puna de Atacama (2900 msnm): Tulan 52 y Tulan 122. Para ello, se propone una metodología enfocada en el registro y análisis de variables morfométricas y tipológicas del conjunto de objetos para su eventual comparación entre ambas áreas. Los resultados permiten dar cuenta de vínculos materiales de los cazadores-recolectores de una extensa región, así como también reflexionar sobre los sistemas de circulación e intercambio en el Arcaico Tardío.

\section{ANTECEDENTES REGIONALES Y OBJETOS PERFORADOS EN LOS 6000-3500 AP}

El período que va de los 6000 a los $3500 \mathrm{AP}$, denominado también Arcaico Tardío, se ha definido como un momento de creciente complejidad social en el desierto de Atacama (Núñez \& Santoro 2011). Este rango temporal se caracteriza por la especialización productiva, la intensificación en la ocupación de los espacios, la reducción de la movilidad residencial, la ampliación y diversificación tecnológica, la presencia de formas incipientes de manejo de animales, nuevas formas de expresión simbólica y una expansión de las esferas de relaciones sociales (True 1975; Druss 1978; Mena 1981, 1984; Núñez 1982; Núñez \& Santoro 1988; Yacobaccio 2004, 2006; Cartajena et al. 2007; Gallardo 2009; de Souza et al. 2010; Jackson \& Benavente 2010; Núñez \& Santoro 2011; Ballester \& Gallardo 2011; Ballester et al. 2014a, 2014b, 2017).

Los antecedentes de esta época en el desierto de Atacama nos muestran que en cada nicho ecológico existieron modos de vida marcadamente diferentes. En este contexto, la especialización productiva cobra un rol fundamental para el ordenamiento de la nueva sociedad (True 1975, Mena 1981, Ballester \& Gallardo 2011). Así, en las quebradas de la precordillera asociadas a los oasis del salar de Atacama, como el caso de Puripica-1 y Tulan-52, el predominio de puntas lanceoladas, cuchillos bifaciales, raederas, perforadores y raspadores, sumado a la abundante presencia de restos óseos de camélidos, expresan actividades especializadas de caza que derivaron eventualmente en la domesticación incipiente de dichos animales (Núñez 1982; Cartajena 1994; Núñez et al. 1995, 1999, 2006; de Souza 2006; Cartajena et al. 2007; de Souza et al. 2010). Situación similar se ha observado 


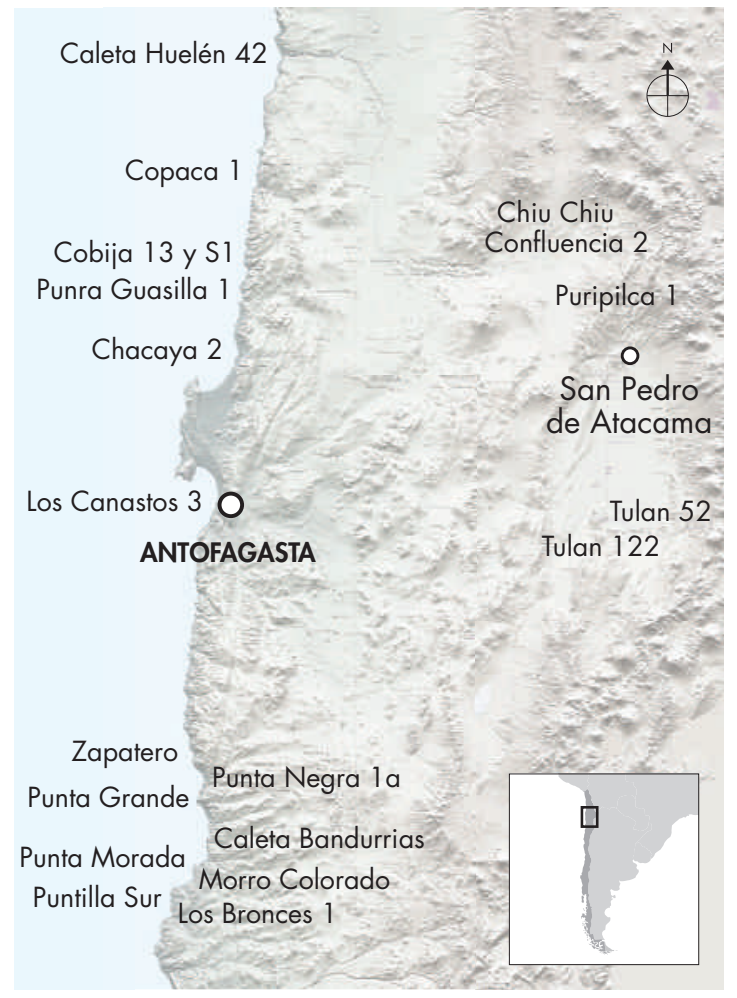

Figura 1. Mapa de sitios y localidades mencionadas en el texto. Figure 1. Map of sites and places mentioned in the text.

en el Loa medio y superior, área cercana a Calama, Chiu-Chiu y El Salado con campamentos vinculados a cazadores especializados de camélidos en un momento previo al desarrollo de las primeras manifestaciones de pastoreo (Druss 1978; Mena 1981; Jackson \& Benavente 1994, 2010; de Souza 2004, 2006, 2014). La construcción de recintos de piedra de patrón circular es una constante en este período y logra su mayor expresión en el sitio Tulan-52 (Núñez 1982, de Souza et al. 2010).

Por otra parte, a lo largo de la costa arreica se populariza un patrón habitacional compuesto por estructuras circulares de piedra bajo cuyos pisos se enterraba a los difuntos de la comunidad (Schaedel 1957; Núñez 1974; Núñez et al. 1974; Zlatar 1983, 1987; Núñez \& Santoro 2011; Ballester et al. 2014a, 2017; Salazar et al. 2015). Este tipo de ocupación del espacio se vuelve común a partir de los $6000 \mathrm{AP}$, manteniéndose vigente hasta al menos los 3500 AP en una amplia región. Campamentos de estas características han sido identificados en la desembocadura del río Loa (Núñez, L. 1971; Núñez, P.1974; Núñez et al. 1974; Zlatar 1983, 1987), Copaca
(Castro et al. 2012, Olguín et al. 2015), en la caleta Cobija (Cruz \& Bravo 1980; Montenegro 1982; Bittmann 1984; Bittmann \& Munizaga 1984; Castro et al. 2012, 2016) y en las áreas de Mejillones (Bustos 1974; Ballester et al. 2014a, 2017), Antofagasta (Llagostera 1989, Cruz \& Llagostera 2011, Ballester et al. 2014b) y Taltal (Capdeville 1921; Latcham 1939; Mostny 1964; Castelleti 2007; Contreras et al. 2007, 2008, 2011; Power 2015; Salazar et al. 2015) (fig. 1).

El yacimiento costero más representativo de este período corresponde a Caleta Huelén 42, sitio residencial que evidencia una fuerte especialización en la explotación de los recursos marinos, expresada en una compleja tecnología de pesca y caza marina, con pesas para lienza, poteras, anzuelos simples y compuestos, arpones de hueso y madera y hojas-líticas tipo taltaloide (Núñez, L. 1971; Núñez, P. 1974; Núñez et al. 1974; Zlatar 1983, 1987).

Dentro de este contexto histórico los bienes con objetos perforados se vuelven un artefacto importante para la vida social de las comunidades del amplio territorio extendido entre la costa y las quebradas prepuneñas de Atacama. En el litoral, por ejemplo, algunos de los ajuares de los contextos fúnebres presentan ingentes collares de cuentas de concha (figs. 2-4), y en los basurales domésticos se identificaron objetos perforados discoidales terminados, preformas y perforadores líticos, como parte de una industria local especializada en su manufactura (Capdeville 1921, Latcham 1939, Bird 1943, Mostny 1964, Núñez 1974, Núñez et al. 1974, Castelleti 2007, Ballester et al. 2014b, Olguín et al. 2015). Objetos perforados discoidales de concha han sido recuperados en las excavaciones arqueológicas de Caleta Huelén 42 (Núñez et al. 1974), Copaca 1 (Olguín et al. 2015, Castro et al. 2016), Chacaya II (Bustos 1974, Ballester et al. 2014a), Los Canastos 3 (Cruz \& Llagostera 2011, Ballester et al. 2014b); en los diferentes cementerios y basurales de Taltal como aquellos cercanos a Muelle de Piedra (Punta Morada, Morro Colorado, Primer Palo Telégrafo, Linderos Bajo, El Caserón) y a Puntilla Sur (Cementerio del Arenal y de la Pipa Tubular) (Capdeville 1921, Latcham 1939, Bird 1943, Mostny 1964); y en los sitios Los Bronces-1 (Latcham 1939, Mostny 1964, Contreras et al. 2007), Punta Negra 1a (Contreras et al. 2011) y Caleta Bandurrias (Mostny 1964, Power 2015) (fig. 1).

Los objetos perforados de concha también comenzaron a destacarse en zonas interiores del desierto 


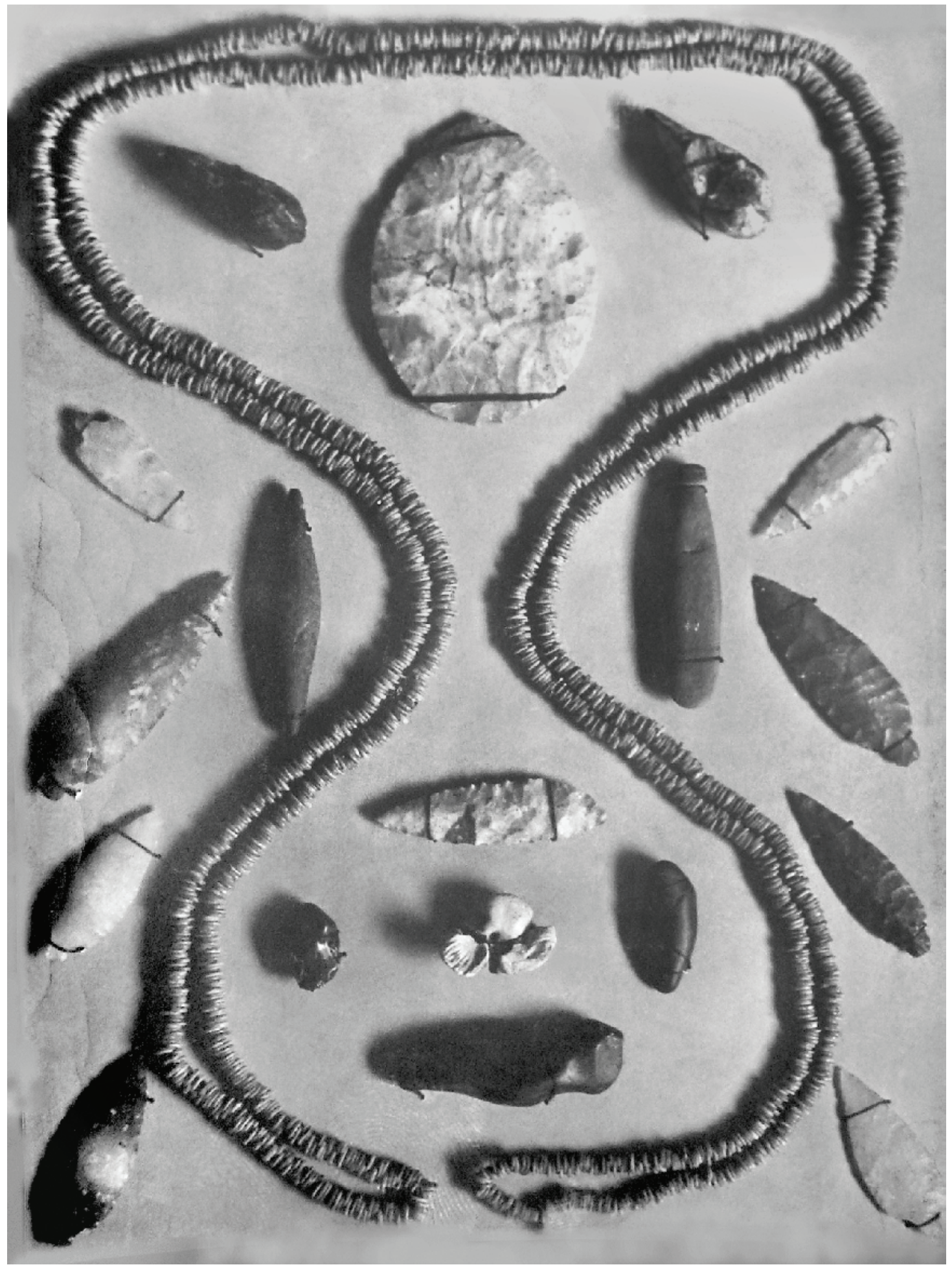

Figura 2. Collar de cuentas proveniente de las excavaciones de Augusto Capdeville en el sitio de Caleta Bandurrias al norte de Taltal (Capdeville s. f.: lám. 15). Figure 2. Bead necklace from excavations performed by Augusto Capdeville at the Caleta Bandurrias site, north of Taltal (Capdeville n.d.: plate 15). 
de Atacama como un atractivo bien de consumo. En el curso medio del río Loa, ubicado casi a $170 \mathrm{~km}$ de la costa, existen importantes evidencias de contactos costa-interior por la presencia de restos óseos de peces marinos y valvas de moluscos (Druss 1978, Mena 1981, Benavente 1988-1989). Un ejemplo de esto es el sitio Confluencia 2 donde se hallaron algunos objetos perforados discoidales manufacturados con valvas de moluscos marinos (Orellana 1965; Jackson 1993-1994; Jackson \& Benavente 1994, 2010). Por su parte, el sitio Chiu-Chiu cementerio reveló valvas de distintas especies de moluscos marinos y algunos objetos perforados en la misma materia prima (Jackson \& Benavente 2010).

En el caso de las quebradas prepuneñas que conectan la alta puna con el salar de Atacama, también se registran objetos perforados de concha. Aquí destacan los contextos de quebrada Tulan, que han permitido documentar los procesos de cambio experimentados por las poblaciones altoandinas durante el tránsito hacia formas culturales más complejas (Núñez et al. 2006, Cartajena et al. 2007, de Souza et al. 2010). Los sitios más significativos para el Arcaico Tardío son Tulan 52 y Tulan 122, pues evidencian una intensa producción artesanal de objetos perforados en diferentes materias primas, que se asocian a abundantes microperforadores líticos y a conchas de Oliva peruviana, posiblemente utilizadas como cuentas o colgantes (Núñez et al. 2006, Soto 2009, de Souza et al. 2010).

Por su parte, en la puna del Noroeste de Argentina, casi a $500 \mathrm{~km}$ del litoral Pacífico, existen importantes sitios arqueológicos con presencia de objetos perforados en conchas del oceáno Pacífico (Yacobaccio 2004, 2006; Mondini et al. 2013). Estos elementos han sido registrados desde los 8000 años AP en Antofagasta de la Sierra (Catamarca) (Mondini et al. 2013), consolidándose su ubicuidad en distintos contextos de la quebrada de Humahuaca (Jujuy) hacia los 6000 AP. De esta manera, el sitio Inca Cueva 4 reporta la existencia de objetos perforados en valvas de moluscos del Pacífico y gastrópodos terrestres (Strophoechelius oblongus) como parte de ajuares mortuorios (Yacobaccio 2004, 2006; Pírola et al. 2015). Por su parte, las excavaciones de Inca Cueva 7 revelaron distintos tipos de objetos perforados de concha, entre los que se encuentran algunos ejemplares manufacturados con especies marinas (Oliva peruviana) (Aguerre et al. 1973, Aschero \& Yacobaccio 1998-1999). Adicionalmente, en un contexto mortuorio de la capa E2 (entierro 3),

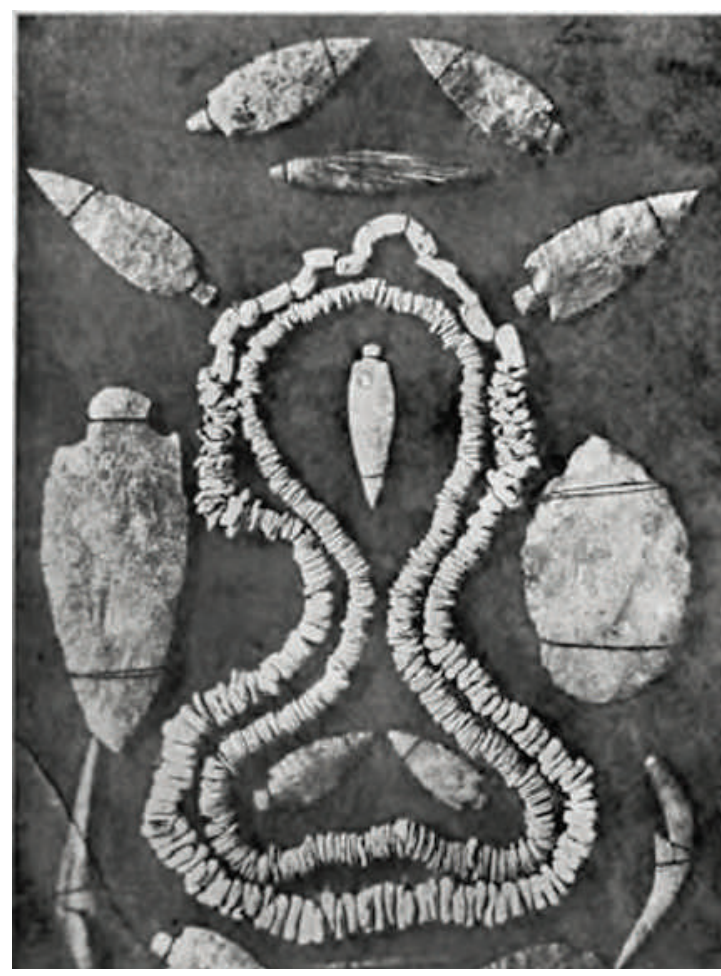

Figura 3. Collar de cuentas proveniente de las excavaciones de Augusto Capdeville en el sitio de Los Bronces al sur de Taltal (Latcham 1939: lám. 5). Figure 3. Bead necklace from excavations performed by Augusto Capdeville at the Los Bronces site, south of Taltal. (Latcham 1939: plate 5).

del sitio Huachichocana III, se hallaron collares con objetos perforados de hueso y conchas del Pacífico, algunos de ellos realizados sobre valvas completas (Oliva peruviana y Argopecten purpuratus) (fig. 5) (Fernández-Distel 1986, Lema 2017).

En este contexto, la ubicua presencia de elementos fabricados con conchas marinas en escenarios geográficos diversos y en espacios de alto valor simbólico merece una discusión más detallada. A partir del estudio y comparación de aspectos tecnomorfológicos de un conjunto de objetos perforados procedentes de yacimientos de la costa pacífica y del salar de Atacama, esbozamos planteamientos sobre las relaciones sociales establecidas durante el período en estudio entre comunidades con modos de vida distintos y asentadas a más de $250 \mathrm{~km}$ de distancia. 


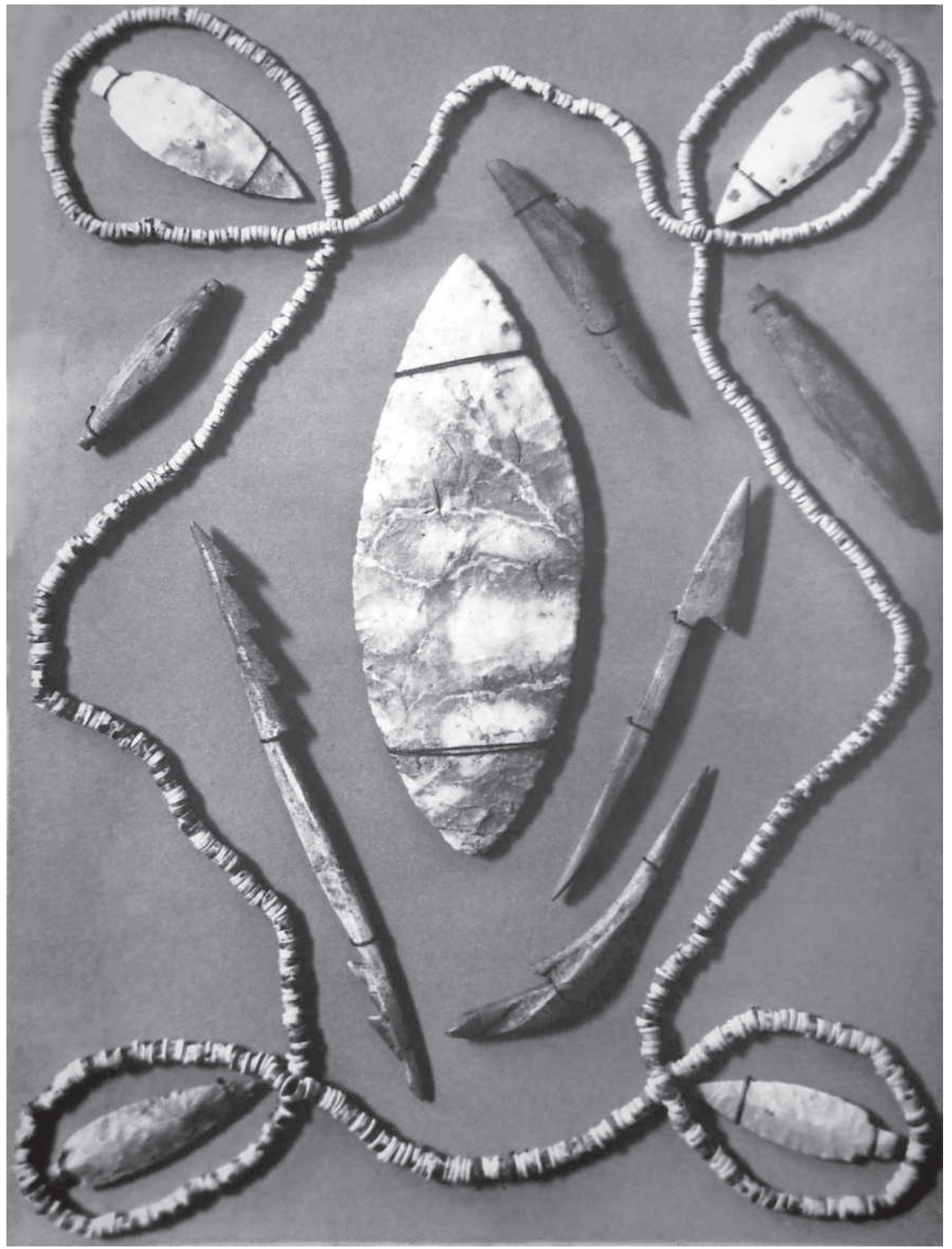

Figura 4. Collar de cuentas proveniente de las excavaciones de Augusto Capdeville en el sitio de Punta Morada, justo al norte de Taltal (Capdeville s. f.: lám. 16). Figure 4. Bead necklace from excavations performed by Augusto Capdeville at the Punta Morada site, just north of Taltal (Capdeville n.d.: plate 16). 
a

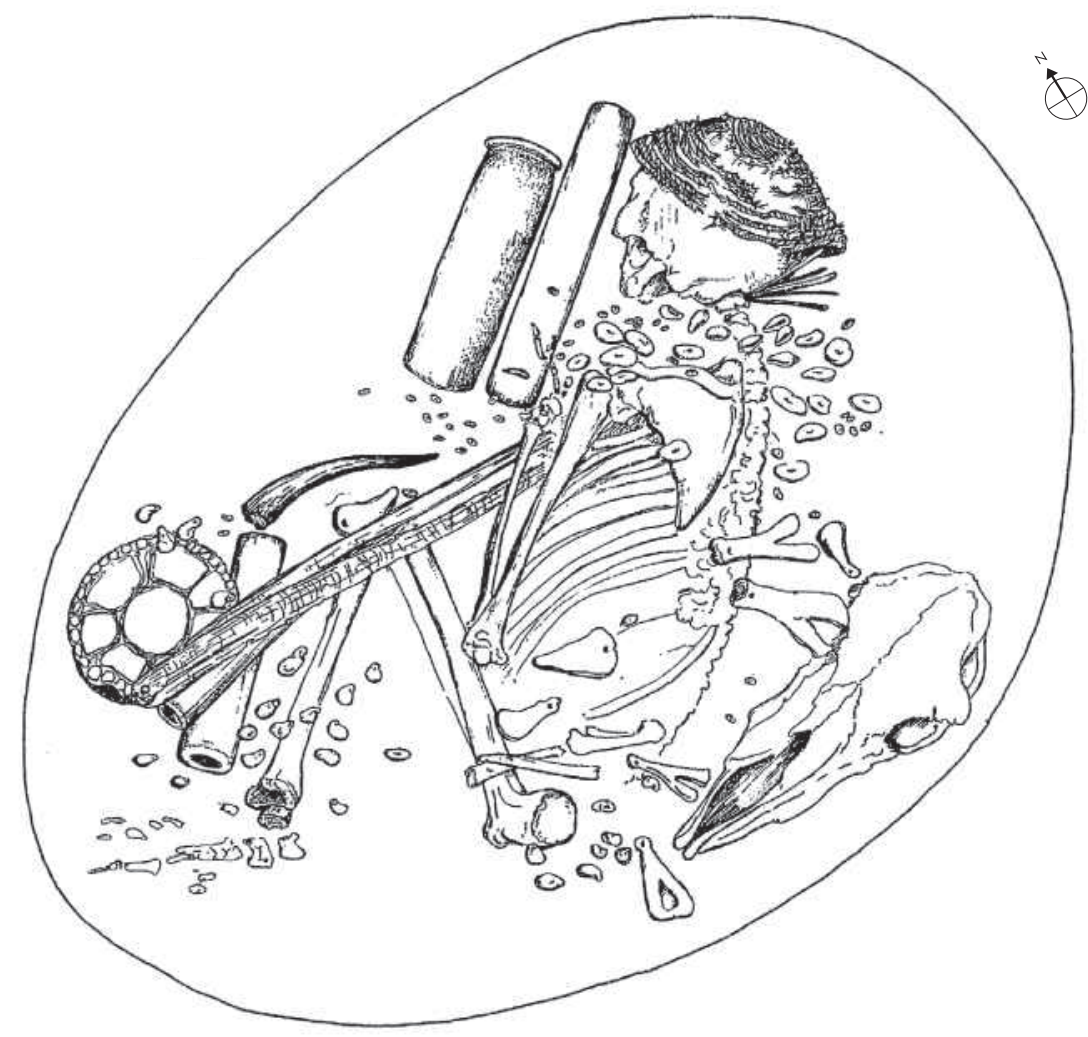

b

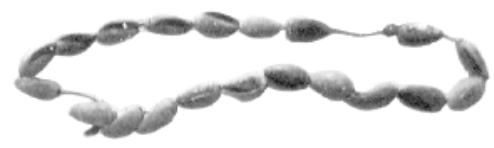

d

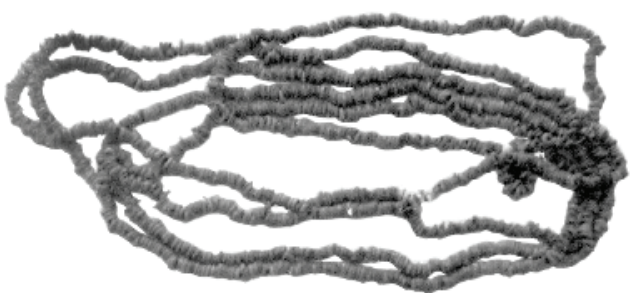

C

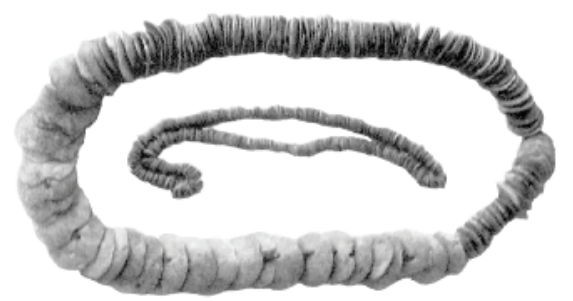

e

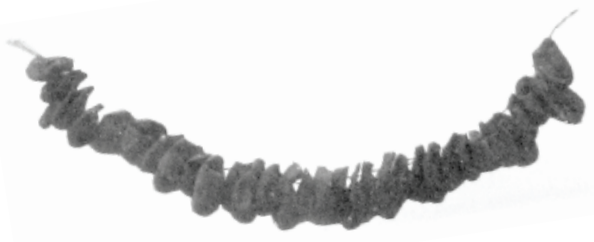

Figura 5. Cueva de Huachichocana III, Capa E2, entierro 3: a) croquis contexto fúnebre (Fernández-Distel 1986: fig. 5-1); b-e) collares asociados al entierro 3 (Fernández-Distel 1986: fig. 8), de los cuales (b) presenta valvas de Oliva peruviana y (d) de Argopecten purpuatus (Fernández-Distel 1986: 391-392, fig. 8). Figure 5. Cave Huachichocana III, Layer E2, burial site 3: a) sketch of the burial context (Fernández-Distel 1986: fig. 5-1); b-e) necklaces in burial site 3 (Fernández-Distel 1986: fig. 8), with (b) presenting shells of Oliva peruviana and (d) Argopecten purpuatus (Fernández-Distel 1986: 391-392, fig. 8). 


\section{MATERIAL Y MÉTODO}

Los materiales analizados proceden de trabajos recientes en quebrada Tulan, en el salar de Atacama, y de Taltal, en la costa arreica del norte de Chile (Núñez et al. 2006, de Souza et al. 2010; Contreras et al. 2011, Salazar et al. 2015), a partir de los cuales los autores han realizado investigaciones específicas (Soto 2006, Contreras et al. 2011, Power 2015).

La muestra se compone de 104 objetos perforados provenientes de cuatro sitios arqueológicos datados entre los 6000 y los 3500 AP (tabla 1). Específicamente, los conjuntos de la costa fueron rescatados de estructuras arquitectónicas de "patrón Caleta Huelén 42" en los sitios Punta Negra la y Caleta Bandurrias, correspondiente a un total de 56 piezas, todas completas. Los conjuntos materiales del interior suman un total de 48 piezas procedentes de distintas excavaciones en los sitios Tulan 52 y Tulan 122, e incluyen ejemplares completos e incompletos.

El conjunto fue analizado considerando la materia prima de las piezas, las que fueron identificadas a través de análisis macroscópico.

El grado de formatización se definió a partir de la etapa productiva en que se encontraban las piezas: terminadas, inconclusas o preformas -identificadas por el grado completitud de la perforación y los bordes-.
Por último, se determinaron las gradientes de atributos métricos. Esta etapa estuvo centrada en la obtención de promedios numéricos por unidad desde los cuales establecer intervalos de frecuencias de tamaño para la realización subsecuente de comparaciones intra e intersitio. En esta fase, se tomaron medidas de distintas secciones de los objetos (diámetro, tamaño de perforación y espesor).

Los tipos morfométricos resultantes son los siguientes:

Rectangulares: piezas que tienden a una forma cuadrangular desde la parte frontal.

Discoidales: piezas circulares cuyo espesor no supera su diámetro. Se han subdividido en cuatro tipos, según tamaño:

Mínima: piezas menores a 3,9 $\mathrm{mm}$.

Pequeña: piezas en el rango 4-6 mm.

Mediana: piezas en el rango 6,1-10 $\mathrm{mm}$.

Grande: piezas de tamaño mayor a $10 \mathrm{~mm}$.

Tabla 1. Distribución de tipos morfométricos de objetos perforados de concha por sitio. Table 1. Distribution of morphometric types of perforated shell objects per site.

\begin{tabular}{|c|c|c|c|c|c|c|c|}
\hline & RECTANGULAR & & & DISCOIDAL & & & TOTAL \\
\hline SITIO & & MÍNIMO & PEQUEÑO & MEDIANO & GRANDE & TOTAL & 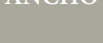 \\
\hline Punta Negra 1a & 3 & & 6 & 17 & & 23 & 26 \\
\hline Bandurrias & 2 & & 2 & 25 & 1 & 28 & 30 \\
\hline Tulan 52 & 2 & & 10 & 14 & 1 & 24 & 26 \\
\hline Tulan 122 & & 1 & 7 & 13 & & 22 & 22 \\
\hline Total general & 7 & 1 & 25 & 69 & 2 & 97 & 104 \\
\hline
\end{tabular}

* Medidas en cms. 


0000
00
000000
00000
00000
00000
000000




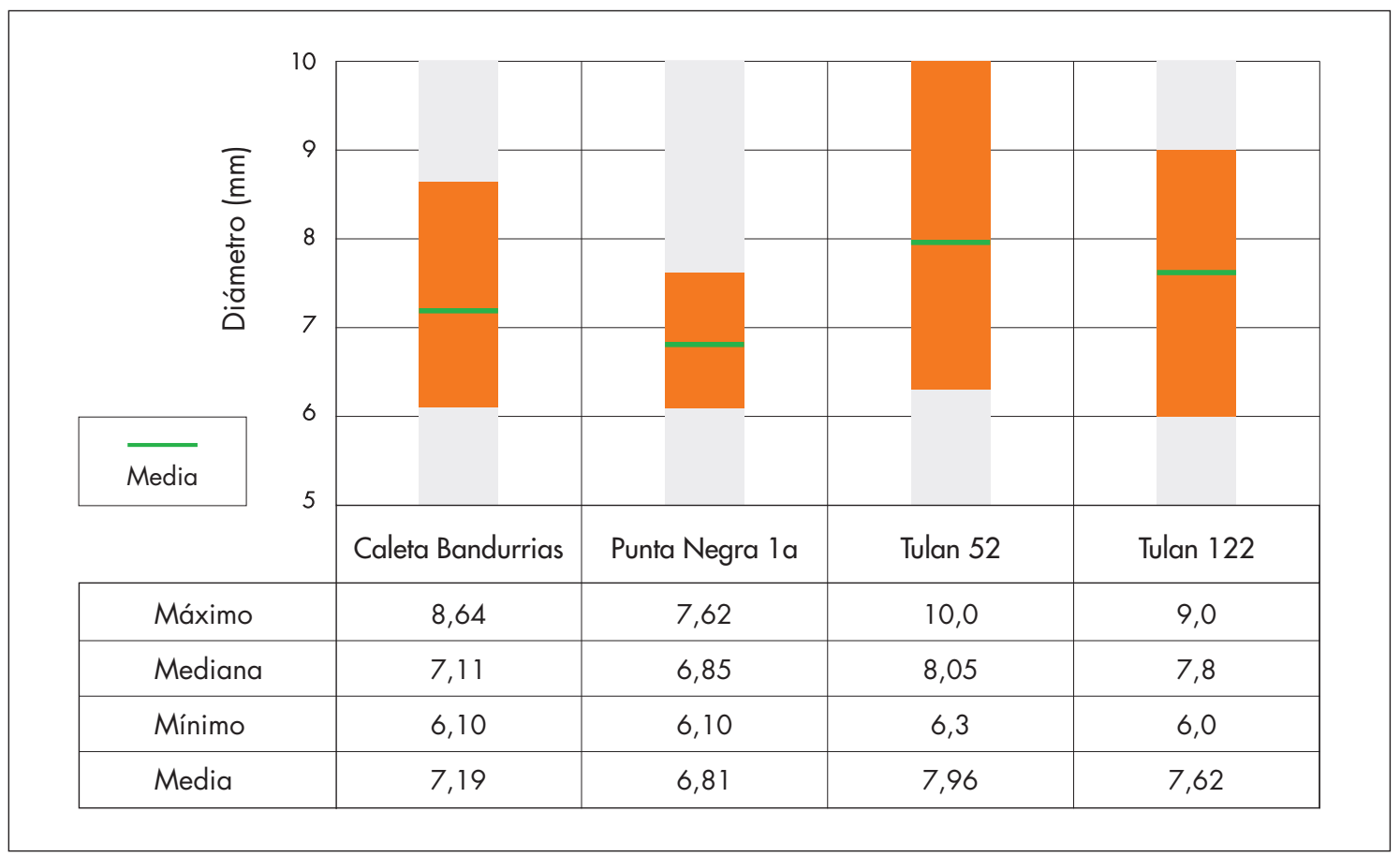

Figura 7. Diámetro ( $\mathrm{mm})$ de cuentas discoidales representadas en cada sitio. Figure 7. Diameter (mm) of discoidal beads represented in each site.

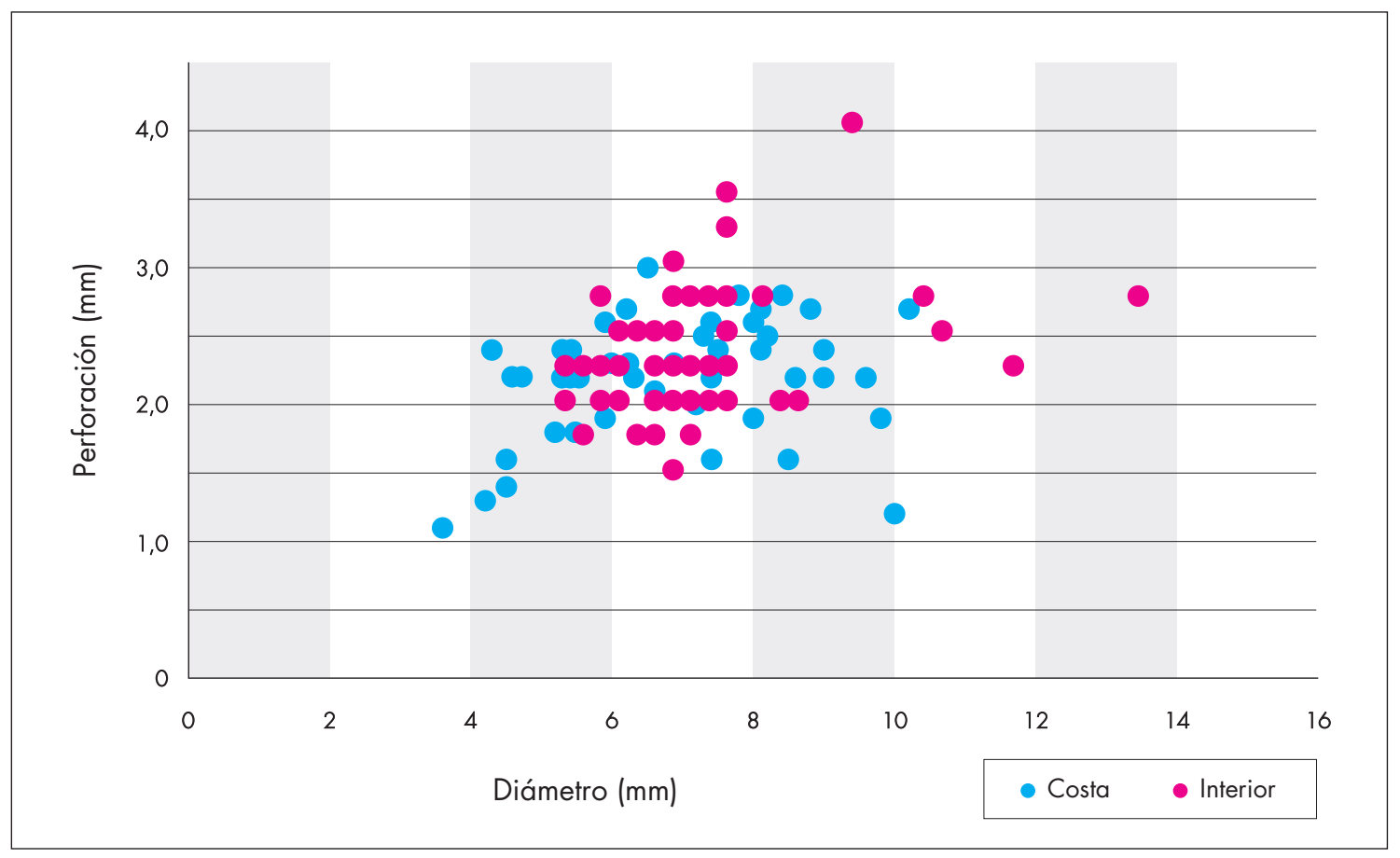

Figura 8. Dispersión de diámetro y tamaño de perforación $(\mathrm{mm})$ de objetos perforados discoidales en sitios de costa e interior. Figure 8. Dispersion of diameter and perforation size $(\mathrm{mm})$ of discoidal perforated objects from both coastal and inland sites. 


\section{RESULTADOS}

El análisis permitió identificar dos tipos de objetos perforados, rectangular y discoidal, facturados con valvas de moluscos marinos. A su vez, se distinguieron algunas diferencias y similitudes entre los conjuntos de estos sitios, las que se ofrecen a continuación.

\section{Los sitios costeros}

Respecto a la variabilidad a nivel de sitio, en Punta Negra 1a se registraron 26 piezas provenientes de la estructura $2(n=3)$ y la estructura $4(n=23)$. Todas corresponden a ejemplares de conchas que no fueron determinadas taxonómicamente debido al tamaño y la obliteración de las superficies por el pulido de la pieza. Las categorías morfométricas identificadas corresponden al tipo rectangular $(n=3)$, discoidal pequeño $(n=6)$ y discoidal mediano $(\mathrm{n}=17)$. El promedio del diámetro de los objetos perforados discoidales es de $6,53 \mathrm{~mm}(\mathrm{ds} 0,64)$ y el de la perforación es de $2,42 \mathrm{~mm}$ (ds 0,341 ).

En Caleta Bandurrias fueron registradas 30 piezas, las que, al igual que en el caso anterior, no pudieron ser identificadas según taxón debido al tamaño y pulido de las superficies. Los tipos corresponden a rectangular $(n=2)$, discoidales pequeñas $(n=2)$, discoidal mediana $(n=25)$ y una discoidal grande $(n=1)$. El promedio del diámetro de los objetos perforados discoidales es de $7,148 \mathrm{~mm}(\mathrm{ds} 0,86)$ y el de la perforación es de 2,28 $\mathrm{mm}$ (ds 0,553$)$.

En términos comparativos, en los conjuntos de Caleta Bandurrias y Punta Negra la el tipo morfométrico predominante es el discoidal, registrándose en frecuencias del $93,3 \%$ para el primer sitio y $88,46 \%$ para el segundo. A nivel métrico, el tipo de mayor frecuencia es el discoidal mediano, presentándose en un $83,3 \%$ en Caleta Bandurrias y 69,23\% en Punta Negra 1a. ${ }^{1}$ En cuanto a los tamaños de las piezas del tipo discoidal mediano, observamos en Caleta Bandurrias un diámetro promedio de $7,19 \mathrm{~mm}(\mathrm{ds} 0,62)$ y una perforación promedio de 2,14 mm (ds 0,58). Por su parte, en Punta Negra 1a el diámetro promedio de los objetos perforados discoidales es de $6,76 \mathrm{~mm}(\mathrm{ds} 0,5)$ y el promedio de la perforación es de $2,25 \mathrm{~mm}$ (ds 0,44 ).

Asimismo, hemos identificado piezas del tipo rectangular, también denominadas en la literatura arqueológica como "subcircular de sección irregular" (Soto 2009) o "cuadrangular con reborde" (fig. 3). En este caso, fueron identificadas tres piezas en Punta Negra 1a y dos en Caleta Bandurrias. En términos tecnológicos, es posible apreciar que este tipo de objetos perforados presentan una sección de mayor tamaño, lo que parece indicar que fueron manufacturadas con las zonas más gruesas de las valvas (Soto 2006).

Aunque los depósitos interiores de las estructuras de ambos sitios se encuentran alterados por procesos postdepositacionales (principalmente de origen antrópico, por reutilización prehispánica y saqueo reciente) y no han sido evidenciados enterratorios in situ, es importante destacar que los objetos perforados de los conjuntos tanto de Caleta Bandurrias como de Punta Negra 1a están en buen estado de conservación y completos. Ello es esperable para piezas provenientes de contextos ceremoniales o fúnebres, funcionalidad que tradicionalmente ha sido propuesta para los sitios con el patrón arquitectónico Caleta Huelén (Capdeville 1921, Mostny 1964, Núñez et al. 1974, Bittman 1984, Contreras et al. 2007, Núñez \& Santoro 2011, Ballester et al. 2017). ${ }^{2}$

\section{Los sitios puneños}

Los objetos perforados de la puna de Atacama expresan mayor variabilidad intersitio. De este modo, el sitio Tulan 52 se compone de 26 piezas provenientes de tres unidades de excavación (1 x $1 \mathrm{~m}$ ). Si bien los objetos perforados recuperados se registran en diferentes materias primas (óseo y mineral de cobre), los elementos fabricados con concha son ampliamente predominantes (Soto 2006). Los ejemplares de concha corresponden al tipo rectangular $(n=2)$, discoidal pequeño $(n=10)$ y discoidal mediano $(\mathrm{n}=14)$. El promedio del diámetro de las piezas discoidales es de $6,78 \mathrm{~mm}(\mathrm{ds} 1,69)$ y el de la perforación es de $2,16 \mathrm{~mm}$ (ds 0,47).

Por otra parte, los elementos analizados de Tulan 122 suman 22 piezas, todas ellas de concha. Los tipos morfométricos corresponden a discoidal mínimo $(\mathrm{n}=1)$, discoidal pequeño $(n=7)$, discoidal mediano $(n=13)$ y discoidal grande $(\mathrm{n}=1)$. El promedio del diámetro de las piezas discoidales es de $6,66 \mathrm{~mm}$ (ds 1,85$)$ y el de la perforación es de 2,29 mm (ds 0,42).

A nivel comparativo, la principal diferencia radica en que los conjuntos de Tulan 122 se componen únicamente de piezas conquiliológicas, mientras que Tulan 52 registra otras materias primas además de los predominantes objetos en concha (Soto 2006). Respecto al conjunto que nos interesa, en Tulan 52 se observan dos 
tipos morfométricos: rectangulares $(\mathrm{n}=2)$ y discoidales, subdivididos en discoidal pequeño $(n=10)$ y mediano $(n=4)$. En Tulan 122 encontramos solo el tipo discoidal en sus cuatro tamaños: mínimo $(n=1)$, pequeño $(n=7)$, mediano $(n=13)$ y grande $(n=1)$.

Como hemos expuesto, el tipo discoidal mediano predomina tanto en Tulan 52 (53,8\%) como en Tulan 122 (59\%). En cuanto a los tamaños de las piezas del tipo discoidal mediano, en Tulan 52 el diámetro promedio es de $7,96 \mathrm{~mm}(\mathrm{ds} 1,15)$ y el promedio de perforación es de $2,29 \mathrm{~mm}$ (ds 0,49), mientras que en Tulan $122 \mathrm{el}$ diámetro promedio es de 7,62 $\mathrm{mm}$ (ds 1,01) y el promedio de perforación es de 2,39 $\mathrm{mm}$ (ds 0,30).

En los cálculos recién presentados no fueron consideradas las piezas fragmentadas debido a que no es posible medir su tamaño total, aunque sí se consideraron en la contabilización total. Es importante señalar esta cualidad, pues, a diferencia de las piezas analizadas para la costa, en los sitios puneños encontramos piezas fracturadas $(32,78 \%)$ y fragmentadas $(8,2 \%)$. Dada la naturaleza del depósito estratigráfico de donde fueron recuperados (áreas de basura), los elementos fracturados y fragmentados corresponderían, más que a componentes de artefactos depositados intencionalmente (p. e., rituales mortuorios), al desecho de actividades artesanales, a elementos deteriorados por uso y a piezas resultantes de un "matado" o quiebre ritual.

\section{Comparación de los conjuntos de costa e interior}

Como se ha delineado, es posible advertir similitudes y diferencias entre los conjuntos del interior y la costa. Por un lado, los objetos perforados de la costa corresponden básicamente a piezas de concha, mientras que en el interior el conjunto analizado de Tulan 52 muestra una mayor variabilidad de materias primas (óseo y mineral de cobre). Esta diferencia debe ser tomada con cautela, pues se conocen contextos de este mismo período que contienen objetos perforados manufacturados en piedra, mineral y hueso en la desembocadura del Loa y en Taltal (Bird 1943, Mostny 1964, Núñez et al. 1974, Contreras et al. 2008, Mengozzi 2016). En los materiales de la costa, el único caso diferente corresponde a una cuenta de tipo tubular que fue manufacturada con materia prima lítica, proveniente de Caleta Bandurrias (Power 2015).

Al considerar el conjunto podemos proponer que, tanto en la costa como en el interior, se encuentran diversos tipos de objetos perforados de concha, predominando las piezas de tipo discoidal $(\mathrm{n}=97)$ por sobre otras $(n=7) .{ }^{3}$ Dentro de los tipos discoidales, aquellos de tamaño mediano (diámetro entre 6,1 y $10 \mathrm{~mm}$ ) son las piezas de mayor frecuencia en ambas áreas, siendo semejantes no solo en términos métricos, sino también en otras cualidades como bordes redondeados, textura y tipo de pulido (fig. 6). A continuación, nos concentraremos en el análisis de las piezas del tipo discoidal mediano de concha, pues nos permiten realizar una comparación tecnológica entre ambos conjuntos.

Los promedios de las piezas del tipo discoidal mediano de concha son relativamente menores en la costa (fig. 7), mientras que en el conjunto de Punta Negra 1a se observa una menor variación en el rango de diámetros. Por ello, nos parece importante recordar que las piezas de este sitio fueron halladas como un rasgo, lo que nos permite asumir que pudieron ser parte de un solo artefacto o collar. Algo similar sucede en Caleta Bandurrias, donde las piezas presentan una variación de tamaño bastante menor. Respecto a los sitios del interior, en ellos se aprecia un rango de variación más amplio, seguramente porque no corresponden a piezas del mismo artefacto (un collar de cuentas puede contar con cientos o miles de piezas). Esta variación se advierte tanto en la distribución de tipos como de materias primas. Como se ha dicho, los conjuntos de Tulan 52 y Tulan 122 son los más heterogéneos, probablemente por la naturaleza de los contextos excavados.

Al realizar un cotejo del conjunto en general, considerando las diferencias entre costa e interior, se observa que la distribución de diámetro y perforación del tipo discoidal mediano de concha es bastante similar en cada uno de los conjuntos (fig. 8). En ambos casos, el diámetro de las perforaciones es prácticamente el mismo: el promedio de las piezas de la costa es de 2,35 mm y el del interior de 2,34 mm, con una variación estándar menor a $0,01 \mathrm{~mm}$. Esta similitud en los tamaños de las perforaciones podría referir a cierta estandarización de los procesos de manufactura de los objetos perforados de concha, ligado seguramente a una tecnología de perforación compartida culturalmente en ambos contextos sociales. 


\section{DISCUSIÓN}

Nuestro estudio da cuenta de la importante presencia de objetos perforados elaborados con conchas del Pacífico -en comparación al uso de otras materias primas como soporte-, tanto en sitios de la costa como del interior del desierto de Atacama, en el rango temporal 6000-3500 AP. Dichos resultados permiten identificar una conexión entre estos espacios distantes a partir del conjunto de materiales $y$, a su vez, posicionar a las poblaciones costeras como agentes fundamentales en la circulación de esta incipiente categoría de objetos (Ballester \& Gallardo 2011).

Destacamos este punto en la discusión, pues la obtención de la materia prima conquiliológica debió requerir habilidades incorporadas en individuos que, en virtud de su permanente relación con el mar, conocieron de manera especializada los bancos de concentración, las técnicas asociadas a la obtención y procesamiento de las valvas, así como las cualidades de estas para ser trabajadas mediante corte, abrasión y pulido, entre otros procedimientos. Por lo tanto, las poblaciones costeras, como antiguas poseedoras de este saber (Llagostera 1989, 2005; Flores et al. 2015; Sarmiento \& Castillo 2017), fueron centrales en la producción de aquellos objetos circulantes, constituyéndose en agentes claves y articuladores en esta naciente red de intercambio regional.

El abastecimiento de valvas debió requerir del dominio de la técnica de recolección costera de moluscos, ya fuese en ambientes intermareales como submareales. Otra posibilidad es que la recolección se realizara indirectamente en orillas de playas, depósitos fósiles o antiguos conchales, cuestión que no podemos descartar. Con todo, ambas circunstancias implicarían un profundo conocimiento del medioambiente costero.

Si bien el avanzado nivel de formatización de las piezas analizadas no permite, de momento, conocer las especies recolectadas, hemos expuesto que las propiedades físicas de ciertas taxas malacológicas (i. e., Argopecten purpuratus y Choromytilus chorus) podrían ser adecuadas para la confección de objetos perforados. Ello se debe a las características de sus valvas con estructura anacarada, color y superficies lisas internas (Soto \& Power 2013), como también a los posibles valores simbólicos asociados a su escasez en las tierras altas (Soto 2009, 2015b), las destrezas implicadas en su obtención por medio de buceo (Trubitt 2003, Soto \& Power 2013, Flores et al. 2015) y la recurrente asociación de estos taxa a contextos funerarios (Soto \& Power 2013). Aun cuando los grupos del interior pudieron proveerse de conchas mediante las alternativas anteriormente señaladas en sus probables visitas a la costa, el acceso al loci de aprovisionamiento debió ser normado, negociado y/o autorizado por las poblaciones habitantes del litoral. Sobre todo, en este momento del pasado prehispánico cuando los límites territoriales parecieran estar materialmente demarcados, como se manifestaría en la práctica arquitectónico-funeraria (Núñez \& Santoro 2011, Power 2015, Ballester et al. 2017).

Por su parte, la similitud entre ambos contextos no solo se aprecia en la materia prima, sino también en diferentes atributos métricos y morfológicos de los conjuntos, lo cual nos permite inferir la presencia de cierto estándar normativo en la producción de las mismas. En ambas regiones se observa una notoria preferencia estilística hacia el tipo morfológico discoidal y de rango métrico mediano. De esta manera, podríamos concluir que los objetos perforados discoidales medianos se popularizan en la región costera e interior de Atacama en el marco cronológico propuesto, elección tecnológica que atañe probablemente a aspectos visuales o estéticos asociados con la ornamentación o aplicación de dichos enseres sobre determinados soportes móviles.

A su vez, se evidencia un estándar tecnológico en lo que respecta a los diámetros de perforación de las piezas estudiadas, expresando procesos, herramientas de manufactura y conocimientos prácticos similares sobre el trabajo de las valvas de moluscos. Vale decir que las mencionadas características morfométricas distinguen a estas piezas de las de otros períodos de la secuencia regional, tal como ha sido constatado para el Período Formativo en los sitios de Choluto (Taltal), Tulan 54 (Salar de Atacama) y Chorrillos (Loa Medio) (Soto 2015a). Posiblemente, la relación entre los tamaños de los diámetros de perforación constituya el indicador más decidor en esta asociación tecnológica, ya que este atributo refiere directamente a las características del instrumento perforante y a su utilización, lo que sin duda debiese guiar contrastaciones con análisis líticos y procedimientos experimentales a futuro (Leonardt 2014).

Considerando el conjunto de atributos mencionados, la similitud morfométrica entre los objetos perforados de costa e interior puede ser interpretada de distintas maneras. Por una parte, pudo existir una forma de hacer monopolizada por las comunidades de la costa para su consecuente intercambio con poblaciones de tierras 
altas. Por otra, podría tratarse de una manufactura local basada en modos de hacer compartidos, pero orientados hacia formas finales específicas. De igual modo, pudo haberse desarrollado la conjunción de ambas o más posibilidades.

Cualquiera haya sido la naturaleza de dicho proceso, la presencia de objetos y valvas malacológicas a más de $500 \mathrm{~km}$ de distancia es indicadora de interacción y circulación de grupos humanos entre las tierras altas y la costa (Yacobaccio 2004, 2006; de Souza et al. 2010; Ballester \& Gallardo 2011). Para pensar cabalmente la ruta de estos objetos es preciso considerar que el intercambio entre comunidades no solo permitió la interdependencia económica de los grupos (Spielmann 1986), sino que además la creación consecutiva de espacios sociales de gran escala (Lazzari 2005, Whallon 2006, Smith 2013).

En este sentido, el hallazgo de objetos perforados de concha en la costa y la puna, sumado a las similitudes tecno-morfológicas mencionadas, permiten concluir dos ideas claves en las transformaciones sociales acontecidas en el Período Arcaico Tardío. En primer lugar, se inauguran y sistematizan las esferas económicas entre costa e interior, en que la circulación de un producto de origen costeño se instala como objeto de relevancia (Ballester \& Gallardo 2011). En segundo lugar, los objetos perforados constituyen unos de los primeros bienes formatizados estandarizados que circulan en un ámbito macrorregional, situación que no había sido observada en períodos anteriores ni tampoco en otros objetos muebles.

Por lo tanto, es posible sugerir que durante el Arcaico Tardío se inaugura la producción de bienes conquiliológicos formatizados de valor intercambiable, los cuales tienen una distribución por una amplia zona del desierto de Atacama. Esta situación indica probablemente el inicio de las distintas formas de movilidad e intercambio de bienes que se intensifican con claridad en el Período Formativo (Pimentel et al. 2011, Nielsen 2013, Labarca et al. 2015, Pestle et al. 2015, Gallardo et al. 2017) y que se concretan con la circulación de estos objetos en la macroescala, incluyendo interacciones con poblaciones del NOA (Yacobaccio 2004, 2006; de Souza et al. 2010; Mondini et al. 2013).

Los datos aquí expuestos pueden verse fortalecidos por las similitudes entre los conjuntos de la costa y el interior en diferentes elementos de su cultura material (Ballester \& Gallardo 2011). De esta manera, en ambas áreas geográficas se han señalado patrones arquitectónicos afines, representados en las estructuras de piedra circulares socavadas de lajas verticales y horizontales (Núñez et al. 1974, Zlatar 1983, de Souza et al. 2010, Ballester \& Gallardo 2011). A su vez, la presencia de elementos exóticos en la costa como obsidianas y plumas de aves cordilleranas, o de paneles de arte rupestre de estilo puneño (Kalina-Puripica) e incisiones típicas costeras, refuerzan estas asociaciones (Núñez et al. 1974, Ballester et al. 2017, Ballester \& Gallardo 2011, Núñez \& Contreras 2011, Núñez 2016).

Considerando lo anterior, es posible que nos encontremos frente a un momento de particular intensificación en la relación entre los grupos habitantes de la costa y el interior, espacios distantes, lo cual se manifestaría no solo en los diferentes objetos de intercambio, sino también en los imaginarios, conceptos y conocimientos que comparten, instaurados en esta vasta extensión del desierto (Mac Eachern 1994, Ballester \& Gallardo 2011). Develar las rutas y los flujos de información que posibilitaron dichas relaciones es una tarea que permitirá conocer con mayor detalle los vínculos efectivos entre poblaciones litorales y puneñas en momentos previos a la sistematización de los sistemas caravaneros.

En consecuencia, grupos humanos, valvas marinas, objetos perforados de concha y los conocimientos implicados en esta emergente tecnología comienzan a circular por el desierto más árido del mundo a partir del $6000 \mathrm{AP}$, consolidando una esfera de relaciones insoslayable en la posteridad. De este modo, la circulación de objetos perforados de concha aparece como uno de los fenómenos fundacionales en la historia de relaciones de las comunidades costeras e interiores del desierto de Atacama.

La circulación de objetos perforados representa adicionalmente la antesala de una consecuente y compleja tecnología lapidaria en la Puna de Atacama. Durante el Formativo (3500-1500 AP) las relaciones interregionales se incrementarían, asociándose a dicho proceso labores especializadas en la manufactura e intercambio de objetos perforados en distintos puntos de la región (Inferior, Medio y Alto Loa, El Salado, San Pedro de Atacama, quebrada Tulan, Tarapacá, Guatacondo). Esta tecnología se diversificará en períodos posteriores hacia otras formas, tamaños y materias primas, hasta convertirse en una categoría de objetos de fundamental relevancia en las economías de circulación del desierto (Rees 1999; Carrasco 2002; Rees \& de Souza 2004; Soto 2006, 2015a; García-Albarido 2007; Carrión 2010, 2015; Ballester \& Clarot 2014). 


\section{NOTAS}

${ }^{1}$ Tipo morfométrico que ha sido considerado en otras publicaciones como representativo del Período Arcaico Tardío (Soto 2006).

${ }^{2}$ En Caleta Bandurrias, la Estructura-1 reporta osamentas humanas desarticuladas, teñidas de pigmento rojo en todas las capas estratigráficas que componen el interior del recinto arquitectónico. Aunque la integridad de los depósitos está alterada por saqueo, se deduce la presencia de enterratorios asociados a dos oquedades en el piso estéril de la estructura (Power 2015).

${ }^{3}$ La mayoría corresponde al tipo rectangular con reborde.

RECONOCIMIENTOS Agradecemos a los proyectos FONDECYT $1020316,1080666,1160045$ y FONDAP 15110006, y adiconalmente a Rodolfo Contrerars, Director del Museo Augusto Capdeville Rojas de Taltal.

\section{REFERENCIAS}

Aguerre, A., A. Fernández-Distel \& C. Aschero. 1973. Hallazgo de un sitio acerámico en la quebrada de Inca Cueva (Provincia de Jujuy). Relaciones de la Sociedad Argentina de Antropología 7: 197-235.

Aschero, C. \& H. Yacobaccio. 1998-1999. 20 años después: Inca Cueva 7 reinterpretado. Cuadernos del Instituto Nacional de Antropología y Pensamiento Latinoamericano 18: 7-18.

Ballester, B. \& F. Gallardo. 2011. Prehistoric and historic networks on the Atacama desert coast (northern Chile). Antiquity 85: 875-889.

Ballester, B. \& A. Clarot. 2014. La gente de los túmulos de tierra. Santiago: Marmot Impresores.

Ballester, B., A. Clarot \& V. Bustos. 2014a. Chacaya 2: reevaluación de un campamento Arcaico Tardío (6000 al 4000 Cal AP) de la costa de Mejillones, ir Región, Chile. Werkén 15: 31-48.

Ballester, B., A. Clarot, V. Bustos, A. Llagostera \& H. Garcés. 2014b. Arqueología de la prehistoria de la península de Mejillones: el campamento de Los Canastos 3 desde sus cuadernos de campo y materiales de museo. Boletín de la Sociedad Chilena de Arqueología 43-44: 5-21.

Ballester, B., E. Calás, C. Pelegrino, E. Vidal \& P. Aguilera. 2017. La vida en comunidad de los cazadorespescadores marinos del desierto de Atacama (4000-2000 cal. AC). En Monumentos funerarios de la costa del desierto de Atacama. Los cazadores-recolectores marinos (norte de Chile), F. Gallardo, B. Ballester \& N. Fuenzalida, Eds., pp. 183-197. Santiago: ICIIS-SCHA.

Benavente, A. 1988-1989. Nuevas evidencias arqueológicas acerca de los asentamientos tempranos en el Loa Medio. Paleoetnológica 5: 65-72.
BIRD, J. 1943 Excavations in northern Chile. Anthropological Papers of the American Museum of Natural History 38 (4): 173-318.

Bittmann, B. 1984. El Proyecto Cobija: investigaciones antropológicas en la costa del desierto de Atacama. Simposio Culturas Atacameñas. En Actas del $44^{\circ}$ Congreso Internacional de Americanistas, pp. 99-146. Manchester.

Bittmann, B. \& J. Munizaga. 1984. Evolución en poblaciones precolombinas de la costa norte de Chile. Chungara 13: 129-142.

Bustos, V. 1974. Chacaya II: una aldea temprana sin agricultura y sin cerámica. Arqueológica 2: 12-41.

CApdeville, A. 1921. Notas acerca de la arqueología de Taltal II. Boletín de la Academia Nacional de Historia 2: 1-23.

CARrasco, C. 2002. Las industrias líticas de Quillagua durante el Período Formativo, en el contexto del Norte Grande. Estudios Atacameños 22: 33-57.

Carrasco, C., J. Echeverría, B. Ballester \& H. Niemeyer. 2015. De pipas y sustancias: costumbres fumatorias durante el Período Formativo en el litoral del desierto de Atacama (norte de Chile). Latin American Antiquity 26 (2): 143-163.

CARrión, H. 2010. Caracterización tecno-morfológica de cuentas de mineral de cobre durante el Período Medio en San Pedro de Atacama. Informe de Práctica Profesional. Departamento de Antropología, Universidad de Chile.

CARrión, H. 2015. Cuentas de collar, producción e identidad durante el Período Medio en San Pedro de Atacama. En El Horizonte Medio: nuevos aportes desde el sur de Perú, norte de Chile y Bolivia, A. Korpisaari \& J. Chacama, pp. 265-279. Santiago: IFEA-UTA.

Cartajena, I. 1994. Determinación de restos óseos de camélidos en dos yacimientos del Loa Medio (II Región). Estudios Atacameños 11: 25-52.

Cartajena, I., L. Núñez \& M. Grosjean. 2007. Camelid domestication on the western slope of the Puna de Atacama, northern Chile. Anthropozoologica 42 (2): 155-173.

CAstelleti, J. 2007. Patrón de asentamiento y uso de recursos a través de la secuencia ocupacional prehispana en la costa de Taltal. Tesis para optar al grado de magíster en Antropología. San Pedro de Atacama: Universidad Católica del Norte-Universidad de Tarapacá.

Castro, V., C. Aldunate \& V. Varela. 2012. Paisajes culturales de Cobija, costa de Antofagasta, Chile. Revista Chilena de Antropología 26 (2): 97-128.

Castro, V., C. Aldunate, V. Varela, L. Olguín, P. Andrade, F. García-Albarido, F. Rubio, P. Castro, A. MaldoNADO \& J. Ruz. 2016. Ocupaciones arcaicas y probables evidencias de navegación temprana en la costa arreica de Antofagasta, Chile. Chungara 48 (4): 503-530.

Contreras, R., J. Cruz, A. Llagostera, H. Garcés, P. Núñez, O. Rodríguez, H. Gárate, \& G. Becerra. 2007. Los Bronces-1: un asentamiento de 5.500 años en la costa de Taltal. Taltal: Fondo de Desarrollo Regional, Museo Augusto Capdeville Rojas de Taltal. 
Contreras, R., J. Cruz, H. Garcés, A. Llagostera, P. NúÑez, O. Rodríguez, G. Becerra \& H. Gárate. 2008. Los Bronces-1: un asentamiento de 5.500 años en la costa de Taltal. Taltalia 1: 61-74.

Contreras, R., P. NúÑez, A. Llagostera, J. Cruz, A. San Francisco, B. Ballester, O. Rodríguez \& G. Becerra. 2011. Un conglomerado del arcaico costero medio del área Taltal Paposo, norte de Chile. Taltalia 4: 7-31.

Cruz, J. \& L. Bravo. 1980. Cobija Sur-1, sitio de ocupación temprana en la costa de Cobija, II Región, Chile. En Cobija: proyecto de investigaciones interdisciplinarias en la costa centro sur andina (Chile), B. Bittmann, Ed., pp. 153-174. Antofagasta: Universidad del Norte.

Cruz, J. \& A. Llagostera. 2011. Prehistoria de Antofagasta. En la ruta de los primeros antofagastinos. Antofagasta: Morgan Impresores.

De Souza, P. 2004. Tecnologías de proyectil durante los Períodos Arcaico y Formativo en el Loa Superior (norte de Chile): una aproximación a partir del análisis de puntas líticas. Chungara, Volumen Especial, tomo i: 61-76.

De Souza, P. 2006. Los sistemas de proyectiles durante el proceso Arcaico Tardío/Formativo Temprano de la Puna de Atacama: una aproximación desde el análisis de las puntas de proyectil de quebrada Tulan. Tesis para optar al grado de Magíster en Antropología, Universidad Católica del Norte-Universidad de Tarapacá, Chile.

De SouzA, P. 2014. Tecnología lítica, uso del espacio y estrategias adaptativas de los cazadores-recolectores del Arcaico Medio en la cuenca superior del río Loa ( 7000-5000 14C AP): nuevos aportes para la comprensión de los procesos culturales de las poblaciones arcaicas de los Andes centro-sur. Tesis para optar al grado de Doctor en Antropología, mención Arqueología, Universidad Católica del Norte-Universidad de Tarapacá, Chile.

De Souza, P., I. Cartajena, L. Núñez \& C. Carrasco. 2010. Cazadores-recolectores del Arcaico Tardío y desarrollo de complejidad social en la puna de Atacama: las evidencias del sitio Tulan-52 (norte árido de Chile). Werkén 13: 91-118.

Domingo, I., D. Fiore, \& S. K. May. 2009. Archaeologies of art: time, place, and identity. En Archaeologies of art: time, place, and identity, S. K. May, D. Fiore \& I. Domingo Sanz, Eds., pp. 15-28. Walnut Creek, cA: Left Coast Press.

Druss, M. 1978. Environment, subsistence and settlement pattern of the Chiu-Chiu Complex (ca. 2700 to 1600 BC) of the Atacama desert, northern Chile. Ph. D. Thesis. Columbia University.

Dupré, G. \& P. Rey. 1978. Reflections on the relevance of a theory of the history of exchange. En Relations of Productions, D. Seddon, Ed., pp. 171-208. Londres: Frank Cass.

EARLE, T. 2002. Bronze Age economics: the beginnings of political economies. Boulder: Westview Press.

Fernández-Distel, A. 1986. Las cuevas de Huachichocana, su posición dentro del Precerámico con agricultura inci- piente del Noroeste Argentino. Beitrage Zur allgemeinen und vergleichenden Archaeologie 8: 353-430.

Flores, C., V. Figueroa \& D. Salazar. 2015. Middle Holocene production of mussel shell fishing artifacts on the coast of Taltal (25 Lat South), Atacama desert, Chile. The Journal of Island and Coastal Archaeology: 1-14.

García-Albarido, F. 2007. Umiñas en el Período Intermedio Tardío y el Tawantinsuyu: Una aproximación a la lapidaria atacameña. Informe de Práctica Profesional, Departamento de Antropología, Universidad de Chile.

Gallardo, F. 2009. Social interaction and early rock art styles in the Atacama desert (northern Chile). Antiquity 83: 619-633.

Gallardo, F., B. Ballester \& N. Fuenzalida. 2017. Monumentos funerarios de la costa del desierto de Atacama. Los cazadores-recolectores marinos (norte de Chile). Santiago: ICIIS-SCHA.

Godelier, M. 1976. Antropología y economía. ¿Es posible la antropología económica?. En Antropología y economía, M. Godelier, Ed., pp. 279-333. Barcelona: Anagrama.

Hayden, B. 1998. Practical and prestige technologies: the evolution of material systems. Journal of Archaeological Method and Theory 5 (1): 3-55.

HirTh, K. 1996. Political economy and archaeology: perspectives on exchange and production. Journal of Archaeological Research 4 (3): 203-240.

JaCKson, D. 1993-1994. Confluencia 2: un campamento de cazadores arcaicos del norte de Chile. Revista Chilena de Antropología 12: 15-24.

JaCkson, D. \& A. Benavente.1994. Secuencia, cambios y adaptación de los cazadores-recolectores de la microcuenca de Chiu-Chiu, provincia del Loa. Chungara 26 (1): 49-64.

Jackson, D. \& A. Benavente. 2010. Complejización de los cazadores recolectores en Chiu-Chiu, Loa Medio (norte de Chile). Estudios Atacameños 39: 5-20.

Joyce, R. 2005. Archaeology of the body. Annual Review of Anthropology 34: 139-158.

KoHL, P. 1975. The archaeology of trade. Dialectical Anthropology 1 (1): 43-50.

Labarca, R., E. Calás, F. Gallardo, B. Ballester \& A. Prieto. 2015. Chaetophractus vellerosus Gray 1865 (Xenarthra, Dasypodidae) en un cementerio de túmulos de la desembocadura del río Loa (Región de Antofagasta, Chile): evidencias de conexiones con el altiplano andino, Período Formativo Tardío (300 AC-500 DC). Estudios Atacameños 50: 47-58.

LAtcham, R. 1938. Arqueología de la región atacameña. Santiago: Prensas de la Universidad de Chile.

Latcham, R. 1939. La Edad de Piedra en Taltal. Boletín del Museo Nacional de Historia Natural 17: 3-32.

LAZZARI, M. 1999. Distancia, espacio y negociaciones tensas: el intercambio de objetos en arqueología. En Sed non satiata, A. Zarankin \& F. A. Acuto, Eds., pp. 117-151. Buenos Aires: Tributo. 
LAZZARI, M. 2005.Traveling objects and spatial images: exchange relationships and the production of social space. En Global archaeological theory: contextual voices and contemporary thoughts, P. Funari, A. Zarankin \& E. Stovel, Eds., pp. 191-210. Nueva York: Kluwer AcademicPlenum Publisher.

LemA, C. 2017. Del objeto al contexto: la(s) capa(s) "e" de Huachichocana III. Chungara 49 (2): 209-226.

LeONARdT, S. 2014. Producción local de cuentas de valva en el bosque del noroeste de Patagonia. Una aproximación desde la arqueología experimental. Relaciones de la Sociedad Argentina de Antropología 39 (2): 463-482.

LlagosterA, A. 1989. Caza y pesca marítima (9.000 a 1.000 AC). En Culturas de Chile. Prehistoria, J. Hidalgo, V. Schiappacasse, H. Niemeyer, C. Aldunate \& I. Solimano, Eds., pp. 57-80. Santiago: Andrés Bello.

Llagostera, A. 2005. Culturas costeras precolombinas en el norte chileno: secuencia y subsistencia de las poblaciones arcaicas. En Biodiversidad marina: valoración, usos, perspectivas. ¿Hacia dónde va Chile?, E. Figueroa, Ed., pp: 107-148. Santiago: Universitaria.

López, S. \& P. Escola. 2007. Un verde horizonte en el desierto. Producción de cuentas minerales en ámbitos domésticos de sitios agropastoriles. Antofagasta de la Sierra (puna meridional argentina). En Producción y circulación prehispánicas de bienes en el sur andino, A. Nielsen, M. Rivolta, V. Seldes, M. Vázquez \& P. Mercolli, Eds., pp. 225-257. Córdoba: Brujas.

MAC EACHern, S. 1994. "Simbolic reservoirs" and inter-group relations: west african examples. The African Archaeological Review 2: 205-224.

Malinowski, B. 1986. Los argonautas del Pacífico occidental. Un estudio sobre comercio y aventura entre los indígenas de los archipiélagos de la Nueva Guinea melanésica. Barcelona: Planeta D’Agostini.

Mauss, M. 1979. Ensayo sobre los dones. Motivo y forma del cambio en las sociedades primitivas. En Sociología y Antropología, pp. 155-258. Madrid: Tecnos.

MenA, F. 1981 Consideraciones en torno a la movilidad de grupos en el Arcaico Tardío; II Región. Tesis de grado para optar al título de Licenciado en Arqueología y Prehistoria, Universidad de Chile, Chile.

Mena, F. 1984. Patrones de movilidad en el Arcaico Tardío: II Región. Estudios Atacameños 7: 25-35.

MengozZI, F. 2016. Hacia una aproximación de las tradiciones tecnológicas de cuentas de las "poblaciones marítimas con arquitectura” en la costa arreica del Norte Grande de Chile. Tesis para optar al título de Arqueóloga, Universidad de Chile, Chile.

Mondini, M., J. Martínez, E. Pintar \& M. Reigadas. 2013. Middle Holocene foraging, mobility and landscape use in the southern argentinean Puna. Hunter-gatherers from Antofagasta de la Sierra, Catamarca, Argentina. Quaternary International 307: 66-73.
Montenegro, N. 1982. Excavación y estudio del sitio arqueológico Punta Guasilla: un asentamiento temprano. Cobija Tocopilla. Tesis para optar al título de Arqueóloga, Universidad del Norte, Chile.

Mostny, G. 1964. Arqueología de Taltal. Epistolario de Augusto Capdeville con Max Uhle y otros. Santiago: Fondo Histórico y Bibliográfico José Toribio Medina.

Nielsen, A. 2007. Bajo el hechizo de los emblemas: políticas corporativas y tráfico interregional en los Andes circumpuneños. En Producción y circulación prehispánicas de bienes en el sur andino, A. Nielsen, M. Rivolta, V. Seldes M. Vásquez \& P. Mercolli, Eds., pp. 393-411. Córdoba: Brujas.

Nielsen, A. 2013. Circulating objects and the constitution of south Andean society (500 BC-AD 1550). En Merchants, markets, and exchange in the pre-columbian world, J. Pillsbury \& K. Hirth, Eds., pp. 389-418. Washington DC : Dumbarton Oaks.

NúÑEZ, L. 1971. Secuencia y cambio en los asentamientos humanos de la desembocadura del río Loa en el norte de Chile. Boletín de la Universidad de Chile 112: 3-25.

NúÑEZ, L. 1982. Asentamientos de cazadores-recolectores tardíos en la puna de Atacama: hacia el sedentarismo. Chungara 8: 137-168.

NúÑEz, L. \& C. SANToro. 1988. Cazadores de la puna seca y salada del área centro sur andina (norte de Chile). Estudios Atacameños 9: 3-59.

NúÑEZ, L. \& C. SANToro. 2011. El tránsito Arcaico-Formativo en la circumpuna y valles occidentales del centro sur andino: hacia los cambios "neolíticos". Chungara 43: 487-531.

NúÑEZ, L., V. Zlatar \& P. NúÑEZ. 1974. Caleta Huelén 42; una aldea temprana en el norte de Chile (nota preliminar). Hombre y Cultura 2 (5): 1-37.

Núñez, L., M. Grosjean, I. Cartajena \& M. Pino. 1995. Proyecto Puripica: reconstrucción multidisciplinaria de eventos holocénicos culturales y ambientales. En Actas del XIII Congreso de Arqueología Chilena, pp. 273-308. Antofagasta: Instituto de Investigaciones Antropológicas, Universidad de Antofagasta.

NúÑez, L., M. Grosjean \& I. Cartajena. 1999. Un ecorrefugio oportunístico en la puna de Atacama durante eventos áridos del Holoceno Medio. Estudios Atacameños 17: 125-174.

Núñez, L., I. Cartajena, C. Carrasco, P. De Souza \& M. Grosjean. 2006. Emergencia de comunidades pastoralistas formativas en el sureste de la puna de Atacama. Estudios Atacameños 32: 93-117.

NúÑEz, P. 1974. Notas sobre la aldea preagrícola Caleta Huelén 42, desembocadura del río Loa. Norte de Chile. Serie Documentos de Trabajo 5: 27-43.

NúÑEZ, P. 2016. Vivir después de soñar. Taltal: Museo Augusto Capdeville Rojas de Taltal.

NúÑEZ, P. \& R. Contreras. 2011. Arte abstracto y religiosidad en el Arcaico costero: Punta Negra 1c, Paposo Taltal, norte de Chile. Taltalia 4: 33-62. 
Olguín, L., V. Castro, P. Castro, I. Peña-Villalobos, J. Ruz \& B. Santander. 2015. Exploitation of faunal resources by marine hunter gatherer groups during the Middle Holocene at the Copaca 1 site, Atacama desert coast. Quaternary International 373: 4-16.

Orellana, M. 1965. Informe de la primera fase del proyecto arqueológico río Salado. Revista de Antropología 3: 81-118.

Patterson, T. 2005. Distribution and redistribution. En $A$ handbook of economic anthropology, J. Carrier, Ed., pp. 194-209. Reino Unido: Edward Elgar.

Peregrine, P. 1991. Some political aspects of craft specialization. World Archaeology 23 (1): 1-11.

Pestle, W., C. Torres-Rouff, F. Gallardo, B. Ballester \& A. Clarot. 2015. Mobility and exchange among marine hunter-gatherer and agropastoralist communities in the Formative Period Atacama desert. Current Anthropology 15 (1): 121-133.

Pimentel, G., C. Rees, P. De Souza \& L. Arancibia. 2011. Viajeros costeros y caravaneros. Dos estrategias de movilidad en el Período Formativo del desierto de Atacama, Chile. En En ruta: arqueología, historia y etnografía del tráfico sur andino, L. Núñez \& A. Nielsen, Eds., pp. 43-81. Córdoba: Encuentro Grupo Editor.

Pírola, M., M. Morales \& H. Yacobaccio. 2015. Condiciones ambientales y ocupaciones humanas en la quebrada de Inca Cueva durante el Holoceno Medio. Cuadernos del Instituto Nacional de Antropología y Pensamiento Latinoamericano 24 (1): 40-58.

Power, X. 2015. Función y estructura del sitio Caleta Bandurrias (Taltal, II Región de Antofagasta). Una evaluación sobre las poblaciones costeras de los "círculos de piedra". Tesis para optar al grado de Arqueóloga, Universidad de Chile.

Price, S. 2008. Adorno. En Diccionario Akal de etnología $y$ antropología, P. Bonté \& M. Izard, Eds., pp. 15-16. Madrid: Akal.

ReEs, C. 1999. Elaboración, distribución y consumo de cuentas de malaquita y crisocola durante el Período Formativo en la vega de Turi y sus inmediaciones, subregión del río Salado, Norte de Chile. En Los tres reinos: prácticas de recolección en el cono sur de América, C. Aschero, A. Korstanje \& R. Vuoto, Eds., pp. 85-98. Tucumán: Instituto de Arqueología y Museo, Universidad Nacional de Tucumán.

ReEs, C. \& P. De Souza. 2004. Producción lítica durante el Período Formativo en la subregión del río Salado. Chungara, Volumen Especial, tomo I: 453-465.

SAHLins, M. 1983. Economía de la Edad de Piedra. Madrid: Akal.

Salazar, D., V. Figueroa, P. Andrade, H. Salinas, L. Olguín, X. Power, S. Rebolledo, S. Parra, H. Orellana \& J. URrea. 2015. Cronología y organización económica de las poblaciones arcaicas de la costa de Taltal. Estudios Atacameños 50: 7-46.

Sarmiento, A. \& C. Castillo. 2017. Artefactos malacológicos en los cementerios de la costa de Antofagasta y el Loa Medio (500 AC-700 DC). En Monumentos funerarios de la costa del desierto de Atacama. Los cazadores-recolectores marinos (norte de Chile), F. Gallardo, B. Ballester \& N. Fuenzalida, Eds. Santiago: ICIIs-sCHA.

SCHAEDEL, R. 1957. Informe general sobre la expedición a la zona comprendida entre Arica y La Serena. En Arqueología chilena. Contribución al estudio de la región comprendida entre Arica y La Serena, R. P. Schaedel, Ed., pp. 1-42. Santiago: Universidad de Santiago.

Smith, M. 2013. The chain of connection: trade and exchange across the interior. En The archaeology of Australia's deserts, M. Smith, Ed., pp. 206-301. Cambridge: Cambridge University Press.

Soto, C. 2006. Cuentas de collar en la quebrada de Tulan, características y diferencias entre los Períodos Arcaico y Formativo. Práctica Profesional, Departamento de Antropología, Facultad de Ciencias Sociales, Universidad de Chile, Chile.

Soтo, C. 2009. Desde el mar y la selva: usos simbólicos de los restos malacológicos en la fase Tilocalar, quebrada Tulan (3500-2500 AP). Tesis para optar al título de Arqueóloga, Universidad de Chile, Chile.

Soтo, C. 2010. Tipología de cuentas de collar en la quebrada de Tulan (salar de Atacama): nueva línea de evidencia para la transición Arcaico-Formativo. En Actas del XVII Congreso Nacional de Arqueología Chilena, tomo II: 11231134. Valdivia: Kultrún.

Soto, C. 2015a. Amuletos en el cuerpo, ofrenda a las huacas: reflexiones sobre cultura material y visual desde los objetos perforados y sus usos en el Período Formativo (1500 AC-800 DC) del desierto de Atacama (II Región, Chile). Tesis para optar al grado de magíster en Artes, mención Teoría e Historia del Arte, Universidad de Chile, Chile.

Soto, C. 2015b. Distribución y significado de los restos malacológicos en la Fase Tilocalar (3130-2380 AP), quebrada Tulan (salar de Atacama, norte de Chile). Estudios atacameños 51: 53-75.

Soto, C. \& X. Power. 2013. Argopecten purpuratus en el contexto de la arqueomalacología de Taltal. Taltalia 5-6: 21-35.

SPAHNI, J. 1967. Recherches archéologiques à l'embouchure du río Loa (Côte du Pacifique-Chili). Journal de la Société des Américanistes 56 (1): 181-239.

Spielmann, K. 1986. Interdependence among egalitarian societies. Journal of Antropological Archaeology 5: 279-312.

Trubitt, M. 2003. The production and exchange of marine shell prestige goods. Journal of Archaeological Research 11 (3): 243-277.

TRUE, D. 1975. Early maritime cultural orientation in prehistoric Chile. En Maritime adaptations of the Pacific, R. Casteel \& G. Quimby, Eds., pp. 89-144. The Hague: Mounton.

WebB, M. 1974. Exchange networks: prehistory. Annual Review of Anthropology 3: 357-383.

Westfall, C., M. Belmar \& C. González. 2010. Aplicación geo-arqueológica de microscopía electrónica y microsonda en piezas metalográficas y líticas del cementerio Regimiento 
Chorrillos de Calama. En Actas del XVII Congreso Nacional de Arqueología Chilena, pp. 835-846. Valdivia: Kultrún.

Whallon, R. 2006. Social networks and information: non"utilitarian" mobility among hunter gatherers. Journal of Anthropological Archaeology 25: 259-270.

YACOBACCIO, H. 2004. Social dimensions of camelid domestication in the southern Andes. Anthropozoologica 39 (1): 237-247.

YACOBACCIO, H. 2006. Social complexity in south andean hunting-gathering society. En Section 17: Préhistoire de l'Amérique. C17.1: Change in the Andes: Origins of social complexity, pastoralism and agriculture, Acts of the XIVth UISPP Congress, University of Liège, pp. 1-5. Oxford: BAR International Series 1524.

ZlataR, V. 1983. Replanteamiento sobre el problema de Caleta Huelén 42. Chungara 10: 21-28.

ZlatAR, V. 1987. Un yacimiento precerámico y su problemática desde la perspectiva de sus recintos habitacionales. Hombre y Desierto 1: 1-36. 